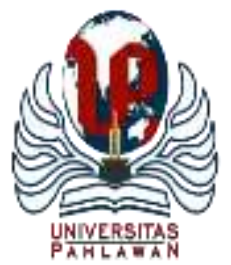

Edukatif : Jurnal Ilmu Pendidikan Volume 4 Nomor 1 Tahun 2022 Halm 786 - 794

EDUKATIF: JURNAL ILMU PENDIDIKAN

Research \& Learning in Education

https://edukatif.org/index.php/edukatif/index

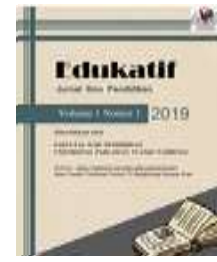

\title{
Analisis Pembaharuan Kurikulum Darurat pada Mata Pelajaran Pendidikan Pancasila dan Kewarganegaraan
}

\author{
Abd. Rohim Asnawi ${ }^{1 凶}$, Kusrini Setyowati ${ }^{2}$, A. Aulia Reski Novianti Alnisyar ${ }^{3}$, Muhammad \\ Holqi Rizki Azhari ${ }^{4}$, Mustiningsih ${ }^{5}$, Agus Timan ${ }^{6}$ \\ Universitas Negeri Malang, Indonesia ${ }^{1,2,3,4,5,6}$ \\ E-mail : asnawialbasyir@gmail.com ${ }^{1}$, rinisdcj@gmail.com $^{2}$, andiaulia12@gmail.com $^{3}$, \\ Holqirizki@gmail.com ${ }^{4}$, mustiningsih.apfipum@yahoo.com $^{5}, \underline{\text { agus.timan.fip@um.ac.id }}^{6}$
}

\begin{abstract}
Abstrak
Kurikulum darurat yang diberlakukan Pemerintah pada masa pandemi Covid-19 belum efektif dalam membentuk karakter siswa pendidikan dasar khususnya melalui Pendidikan Pancasila dan Kewarganegaraan. Tujuan penelitian ini untuk mengetahui permasalahan dan memberikan solusi pada permasalahan pembaharuan kurikulum Pendidikan Pancasila dan Kewarganegaraan. Penelitian ini menggunakan metode penelitian deskriptif dengan pendekatan kualitatif. Lokasi penelitian ini terletak pada SD Katolik Cor Jesu Malang. Hasil penelitian dapat menunjukkan beberapa hal dari permasalahan-permasalahan yang timbul di SD Katolik Cor Jesu Malang tentang pembaharuan kurikulum darurat, seperti guru yang kesulitan dalam menentukan indikator pencapaian hasil belajar, menentukan metode pembelajaran saat online, etika peserta didik dalam proses pembelajaran, kurangnya jam perwalian dalam penyelesaian permasalahan peserta didik secara individu dan para guru masih terbatas dalam hal informasi dan teknologi. Maka dari itu diperlukan inovasi dan penguatan kompetensi guru dalam melaksanakan kurikulum darurat pada Pendidikan Pancasila dan Kewarganegaraan.
\end{abstract}

Kata Kunci: Kurikulum, Pendidikan Karakter, Pendidikan Pendidikan Pancasila dan Kewarganegaraan

\section{Abstract}

The emergency curriculum imposed by the Government during the Covid-19 Pandemic has not been effective in shaping the character of Basic Education students, especially through Pancasila and Citizenship Education. The purpose of this study is to find out the problems and provide solutions to the problems of renewing the Pancasila and Citizenship Education curriculum. This study uses a descriptive research method with a qualitative approach. The location of this research is Cor Jesu Catholic Elementary School, Malang. The results of the study can show several things from the problems that arise in Cor Jesu Catholic Elementary School Malang regarding emergency curriculum renewal, such as teachers who have difficulty determining indicators of learning achievement, determining online learning methods, student ethics in the learning process, lack of guardianship hours. in solving the problems of individual students and teachers are still limited in terms of information and technology. Therefore, it is necessary to innovate and strengthen teacher competence in implementing the emergency curriculum in Pancasila and Citizenship Education.

Keywords: Curriculum, Character Education, Pancasila Education, and Citizenship Education

Copyright (c) 2022 Abd. Rohim Asnawi, Kusrini Setyowati, A. Aulia Reski Novianti Alnisyar, Muhammad Holqi Rizki Azhari, Mustiningsih, Agus Timan

$\triangle$ Corresponding author

Email : asnawialbasyir@gmail.com

DOI : https://doi.org/10.31004/edukatif.v4i1.1824

ISSN 2656-8063 (Media Cetak)

ISSN 2656-8071 (Media Online) 
787 Analisis Pembaharuan Kurikulum Darurat pada Mata Pelajaran Pendidikan Pancasila dan Kewarganegaraan - Abd. Rohim Asnawi, Kusrini Setyowati, A. Aulia Reski Novianti Alnisyar, Muhammad Holqi Rizki Azhari, Mustiningsih, Agus Timan

DOI: https://doi.org/10.31004/edukatif.v4i1.1824

\section{PENDAHULUAN}

Secara umum komponen kurikulum terdiri dari empat komponen utama, diantaranya yaitu: 1. Tujuan yaitu tujuan dari pendidikan nasional, tujuan pendidikan lembaga, tujuan mata pelajaran, dan tujuan instruksional. 2. Bahan, materi atau pengalaman belajar yang mencakup ruang lingkup isi dari kurikulum yang telah disesuaikan dengan jenis, jenjang kelas dan sekolah yang kemudian harus disajikan kepada siswa untuk mencapai tujuan yang telah ditetapkan. 3. Organisasi yaitu merupakan susunan dan urutan dari isi materi dalam kurikulum 4. Evaluasi yaitu sebuah penilaian terhadap hasil dan proses belajar mengajar atau implementasi kurikulum.

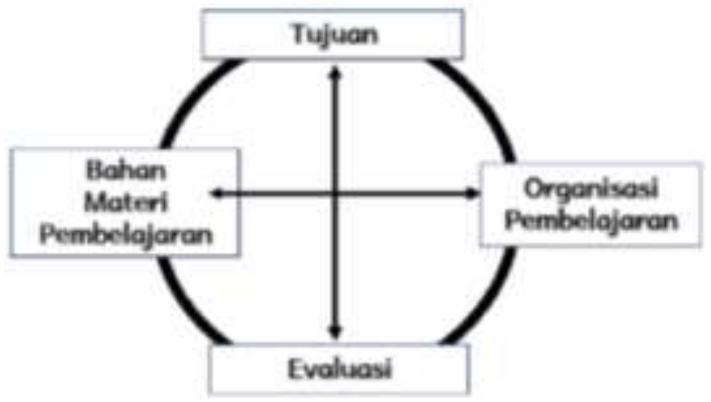

Gambar 1: Komponen Kurikulum

Sumber: (Sudarman, 2019)

Perubahan kurikulum memiliki dampak positif dan negatif terhadap kualitas pendidikan. Dampak positifnya adalah siswa dapat belajar dengan mengikuti perkembangan zaman yang semakin maju, selain itu mereka juga di dukung secara mandiri oleh kepala sekolah, guru, siswa bahkan lembaga pendidikan. Dampak negatifnya adalah siswa tidak mampu beradaptasi dengan sistem pembelajaran kurikulum baru, sehingga mengakibatkan kualitas pendidikan yang buruk dan perubahan kurikulum yang cepat menyebabkan masalah baru seperti nilai siswa yang buruk. (Kurniawan, 2011). Secara biasa praktik-praktik peluasan program studi itu terjalin permulaan ramalan kebutuhan, perumusan tujuan, pengumpulan dan pengaturan materi, pengumpulan dan pengaturan suka duka belajar, dan peluasan perlengkapan evaluasi (Masykur, 2019). Akan tetapi selama masa pandemi ini perubahan kurikulum dihadapkan pada situasi yang berbeda.

Banyak kendala yang dihadapi oleh orang tua, guru dan peserta didik dalam masa pembelajaran jarak jauh. Guru kesulitan dalam pengelolaan pembelajaran jarak jauh, waktu pembelajaran yang berkurang dan kesulitan berkomunikasi dengan orang tua siswa. Di sisi lain, orang tua siswa kurang memiliki kemampuan untuk mengantar anaknya ke sekolah dan sulit bagi orang tua untuk memahami pelajaran siswa. Siswa gagal fokus pada belajar di rumah, mengeluh tentang keseriusan pertanyaan guru, dan meningkatkan stres dan kebosanan yang disebabkan oleh isolasi terus-menerus (Kepmendikbud,2020). Pemerintah telah memperkenalkan dua strategi baru untuk mengantisipasi dampak negatif dan tantangan pembelajaran jarak jauh. Memperluas pelatihan tatap muka untuk zona kuning dan program darurat (dalam kondisi khusus).

Kurikulum Darurat ditetapkan dengan Keputusan Menteri Pendidikan dan Kebudayaan RI No. 719/P/2020. Kebijakan ini memberikan kesempatan kepada sekolah untuk memilih kurikulum yang sesuai dengan kebutuhan belajar siswanya. Kurikulum urgen ini bertujuan untuk mengurangi beban guru dan siswa dalam pelaksanaan kurikulum nasional dalam hal kemajuan pembelajaran dan keputusan kelulusan di semua jenjang pendidikan. (Kepmendikbud, 2020). Namun demikian sekolah masih diberi tiga pilihan dalam implementasinya yaitu 1. Tetap menggunakan kurikulum 2013, 2. Menggunakan kurikulum darurat, 3. Melakukan penyederhanaan kurikulum secara mandiri (Kepmendikbud, 2020).

Kurikulum darurat diharapkan dapat membantu mengurangi hambatan yang dihadapi oleh guru, orang tua dan anak-anak selama pandemi. Tujuan pemberlakuan kurikulum darurat diharapkan dapat menjadi acuan 
788 Analisis Pembaharuan Kurikulum Darurat pada Mata Pelajaran Pendidikan Pancasila dan Kewarganegaraan - Abd. Rohim Asnawi, Kusrini Setyowati, A. Aulia Reski Novianti Alnisyar, Muhammad Holqi Rizki Azhari, Mustiningsih, Agus Timan

DOI: https://doi.org/10.31004/edukatif.v4i1.1824

guru membuat kurikulum yang sederhana, berkurang beban mengajar, lebih berfokus pada hal yang esensial dan kontekstual serta meningkatkan kesejahteraan guru. Bagi siswa diharapkan siswa tidak merasa terbebani pada capaian kurikulum dan meningkatkan psikososial siswa serta bagi orang tua dapat mempermudah pembelajaran dari rumah (Kepmendikbud, 2020). Akan tetapi masalah karakter anak menjadi masalah serius dalam pembelajaran jarak jauh karena guru tidak bisa memantau secara langsung perkembangan siswa.

Siswa sekolah dasar sangat membutuhkan pengembangan karakter untuk perkembangannya, terutama di masa pandemi COVID-19 (Akhwani \& Romdloni, 2021). Strategi pembangunan karakter dapat ditempuh melalui hubungan seperti contoh, pengasuhan dan disiplin, pembiasaan, kesejahteraan, integrasi dan internalisasi, dan kecanduan (Laela, dkk, 2021). Temperamen siswa yang sulit dibentuk dalam pembelajaran online terletak pada pembelajaran sehingga tidak terbentuk karakter disiplin (Suriadi et al., 2021). Hal ini dikarenakan banyak orang tua yang belum memahami seperti apa contoh pendidikan karakter bagi anak, dan para pendidik masih berjuang untuk mengoptimalkan pendidikan karakter di sekolah (Maria et al., 2021). Karakter siswa dapat terwujud dalam bentuk toleransi terhadap perbedaan, artinya sikap dan perilaku siswa menghargai perbedaan agama, ras, suku, pendapat, sikap dan perilaku orang lain selain dirinya (Fahmy et al., 2015). Cakupan isi materi PPKn merupakan kesepakatan pokok antara negara dan negara Indonesia. (Rachman et al., 2021).

Problematika kurikulum Mata Pelajaran Pendidikan Pancasila dan Kewarganegaraan menurut hasil penelitian (Julaeha, 2019) menunjukkan bahwa 1. Kurikulum bukan merupakan patokan yang baku dalam menyesuaikan kondisi, 2. Pendidikan karakter hanya menjadi slogan tanpa ada tindakan dari sekolah, 3. Tidak ada koordinasi antar pelaksana pendidikan karakter yaitu sekolah dan keluarga, 4. Kurang ada peran guru dalam pendidikan karakter disekolah. Penelitian lain dilakukan oleh (Perdana \& Adha, 2020) menunjukkan bahwa teknik blended learning dapat meningkatkan kepribadian. Peningkatan kepribadian dapat dilihat dari peningkatan keterampilan berbicara, berpendapat, dan menanggapi masalah. Anda dapat meluangkan waktu untuk mengakses dan menyelesaikan atau mengumpulkan tugas, tanggung jawab belajar, dan meningkatkan integritas dalam menyelesaikan tugas atau penilaian dari pendidik. Kurikulum etika juga diajarkan di Universitas meskipun tidak diajarkan tidak selalu secara eksplisit disebutkan dalam deskripsi dasar kursus (Kidd et al., 2020).

Penelitian yang dilakukan sebelumnya masih memiliki kelemahan. Penelitian yang dilakukan Julaeha yang berjudul "Problematika Kurikulum dan Pembelajaran Pendidikan Karakter" belum berfokus pada jenjang pendidikan tertentu. Padahal tantangan pendidikan karakter di masing-masing jenjang pendidikan berbeda. Sedangkan penelitian yang dilakukan Perdana hanya berfokus pada pendidikan tinggi. Pendidikan tinggi memiliki tingkat kesiapan yang paling tinggi dalam menerapkan pendidikan jarak jauh. Dengan demikian penelitian ini menarik untuk dilakukan untuk melengkapi kelemahan tersebut. Penelitian ini bertujuan untuk mendeskripsikan permasalahan dan solusi pelaksanaan kurikulum darurat pada Mata Pelajaran Pendidikan Pancasila dan Kewarganegaraan jenjang pendidikan dasar.

\section{METODE PENELITIAN}

Jenis penelitian ini menggunakan jenis penelitian deskriptif dengan pendekatan kualitatif. Penelitian berlokasi di Kota Malang. Lokasi penelitian ini terletak pada SD Katolik Cor Jesu Malang. Penelitian ini menggunakan jenis data primer. Data primer dilakukan dengan melakukan dengan wawancara secara langsung ke informan sedangkan data sekunder diperoleh dengan mengumpulkan hasil studi literatur serta mengecek perubahan kurikulum yang telah dilakukan. Informan dipilih menggunakan teknik Purposive Sampling. Informan yang dipilih ada stakeholder yang terlibat dalam perencanaan dan implementasi kurikulum. Penelitian ini berfokus pada permasalahan dan solusi pelaksanaan kurikulum darurat pada mata 
789 Analisis Pembaharuan Kurikulum Darurat pada Mata Pelajaran Pendidikan Pancasila dan Kewarganegaraan - Abd. Rohim Asnawi, Kusrini Setyowati, A. Aulia Reski Novianti Alnisyar, Muhammad Holqi Rizki Azhari, Mustiningsih, Agus Timan

DOI: https://doi.org/10.31004/edukatif.v4i1.1824

pelajaran Pendidikan Pancasila dan Kewarganegaraan jenjang pendidikan dasar. Analisis data yang digunakan adalah metode analisis interaktif yang dikembangkan oleh Miles, Huberman dan Saldana. Tahapan dalam analisis data oleh oleh Miles, Huberman dan Saldana yaitu dengan kondensasi data (data condensation), penyajian data (data display), penarikan kesimpulan (Conclusions drawing).

\section{HASIL DAN PEMBAHASAN PENELITIAN}

\section{Kurikulum Darurat Pelajaran Pendidikan Pancasila Dan Kewarganegaraan Jenjang Sekolah Dasar}

\section{A. Tujuan Kurikulum}

1. Tujuan pendidikan nasional

Tujuan kurikulum Pendidikan Pancasila dan Kewarganegaraan sesuai dengan tujuan pendidikan nasional.

2. Tujuan institusional

a. Menjadikan siswa dapat berfikir inovatif, kritis dan kreatif.

b. Dengan berbekal teknologi, peserta didik dapat mengoperasikan dan menggunakannya sebagai alat bantu belajar dan berkreativitas.

c. Rata-rata nilai lulusan mencapai 80 dan mendapat nilai maksimum.

d. Peserta didik dapat melanjutkan pendidikan ke jenjang yang lebih tinggi.

e. Seluruh warga Sekolah Dasar Katolik Cor Jesu mampu mewujudkan nilai-nilai SERVIAM dalam kehidupan sehari-hari.

f. Menghargai perbedaan dan keberagaman dan kepedulian terhadap sesama baik dari sisi agama, budaya dan alam sekitar.

g. Meningkatkan kerja sama antar sekolah, masyarakat, dan alumni.

h. Terwujudnya lingkungan sekolah yang nyaman, bersih dan sehat.

i. Menjadikan peserta didik mandiri dan berkarakter.

3. Tujuan kurikuler

a. Menerima, mengamalkan, dan menghormati ajaran agama

b. Bertanggungjawab, disiplin, jujur, sopan, perhatian dan percaya diri dalam berurusan dengan keluarga, teman, guru dan tetangga dan mencintai negara Anda

c. Memahami pengetahuan melalui pengamatan [mendengar, melihat, membaca] dan mengajukan pertanyaan berbasis rasa ingin tahu tentang diri kita sendiri, makhluk Tuhan dan tindakan mereka, dan apa yang kita temui di rumah dan di lingkungan sekolah

b. Menyajikan pengetahuan sesuai bahasa yang logis dan jelas, dalam karya yang estetis, perilaku mencerminkan anak yang sehat dan perilaku mencerminkan anak yang beriman dan berbudi pekerti luhur.

4. Kompetensi Dasar

a. Bersyukur kepada Tuhan YME atas dasar Pancasila

b. Berperilaku bertanggung jawab sesuai dengan Pancasila

c. Menganalisis penerapan Pancasila

d. Mempresentasikan hasil analisis implementasi pancasila

5. Tujuan pembelajaran

a. Peserta didik mampu meyakini Pancasila secara utuh sebagai satu kesatuan. 
790 Analisis Pembaharuan Kurikulum Darurat pada Mata Pelajaran Pendidikan Pancasila dan Kewarganegaraan - Abd. Rohim Asnawi, Kusrini Setyowati, A. Aulia Reski Novianti Alnisyar, Muhammad Holqi Rizki Azhari, Mustiningsih, Agus Timan

DOI: https://doi.org/10.31004/edukatif.v4i1.1824

b. Peserta didik mampu bersikap tanggung jawab sesuai Pancasila

c. Peserta didik mampu menerapkan Pancasila.

d. Peserta didik mampu mengidentifikasi penerapan Pancasila

e. Peserta didik mampu melaporkan analisis pelaksanaan pancasila.

f. Peserta didik mampu menuliskan analisis tentang pelaksanaan pancasila.

\section{B. Komponen Isi}

Komponen isi kurikulum pendidikan Pancasila dan Kewarganegaraan adalah:

a. Meyakini nilai- nilai Pancasila dalam kehidupan

b. Bersikap tanggungjawab berdasarkan Pancasila

c. Mengetahui nilai- nilai Pancasila

d. Mengidentifikasi nilai- nilai Pancasila

e. Melaporkan analisis pelaksanaan nilai- nilai pancasila

f. Menuliskan analisis pelaksanaan nilai- nilai pancasila

Sedangkan SERVIAM VP/CV kurilulum pendidikan Pancasilan dan Kewarganegaraan adalah:

a. Mampu menjadi teladan dalam menerapkan Pancasila

b. Memiliki sikap selektif dalam melaksanakan Pancasila

Sedangkan materi mandiri terdiri atas:

a. Mengerjakan latihan soal penerapan Pancasila

b. Membuat kliping penerapan Pancasila

\section{Organisasi atau Struktur}

Kurikulum mata pelajaran adalah format mata pelajaran yang disusun secara terpisah dari mata pelajaran lain pada waktu tertentu. Waktu pembelajaran mata pelajaran dilaksanakan selama 6 jam pelajaran. Proses pembelajaran dilakukan secara tatap muka dan LSM. Pembelajaran tatap muka dilakukan dengan cara ceramah, observasi, diskusi kelompok, penugasan dan proyek. Sedangkan metode LSM dilakukan melalui Google classroom (Google meet, Video pembelajaran, PPT).

Metode pembelajaran merupakan suatu proses yang sistematis dan teratur yang diikuti oleh pendidik pada saat memberikan materi kepada peserta didik. Kami berharap metode ini akan membuat proses belajar mengajar Anda berjalan lancar. Oleh karena itu, guru harus mampu belajar bagaimana mengajar. Hal ini sangat diperlukan agar siswa terlibat dengan penuh semangat dalam kegiatan pembelajaran di kelas. Bahkan jalan yang benar dapat membuat siswa kurang bosan atau bosan di kelas. Pendidik dapat merasakan manfaat ketika menggunakan pembelajaran yang sistematis dalam proses pengajaran.

\section{Evaluasi}

Penilaian adalah alat ukur untuk menentukan tingkat keberhasilan yang dicapai dalam kaitannya dengan kinerja program dan rencana yang ditetapkan oleh kurikulum. Evaluasi kurikulum dilakukan dengan Penilaian sikap (Penilaian diri dan observasi), Penilaian pengetahuan (Tes tertulis Penilaian harian, tugas harian), Penilaian ketrampilan (Produk, proyek). Selama pelaksanaan kurikulum darurat ini pendidik mengalami kendala dalam proses evaluasi.

Bapak ibu guru wali kelas memiliki jam perwalian untuk membantu menyelesaikan permasalahan anak secara individu. Waktu yang diberikan, sesuai hasil wawancara dan observasi masih kurang sehingga untuk penyelesaian masalah anak masih belum bisa teratasi secara menyeluruh. Metode yang dilakukan oleh bapak dan ibu guru saat jam perwalian adalah melalui telepon, video call atau Whatsapp. Beberapa sumber daya 
791 Analisis Pembaharuan Kurikulum Darurat pada Mata Pelajaran Pendidikan Pancasila dan Kewarganegaraan - Abd. Rohim Asnawi, Kusrini Setyowati, A. Aulia Reski Novianti Alnisyar, Muhammad Holqi Rizki Azhari, Mustiningsih, Agus Timan

DOI: https://doi.org/10.31004/edukatif.v4i1.1824

manusia yang masih terbatas terutama dalam IT sehingga menghambat proses pembelajaran juga membuat pembelajaran kurang menarik sehingga membuat anak-anak menjadi bosan atau bahkan malas untuk mengikuti kegiatan pembelajaran.

\section{Permasalahan Implementasi Kurikulum Darurat Pelajaran Pendidikan Pancasila Dan Kewarganegaraan Jenjang Sekolah Dasar}

Bapak ibu guru yang masih kesulitan dalam menentukan indikator pencapaian hasil belajar bisa dibantu dengan adanya kegiatan KKG/Kelompok Kerja Guru/ tutor sebaya atau kegiatan workshop dengan mengundang narasumber. Pelaksanaan kegiatan KKG/tutor sebaya dilakukan dengan cara bapak ibu guru yang sudah mahir dalam membuat indikator pencapaian kompetensi diminta membantu pendidik yang mengalami kesulitan dalam membuat indikator pencapaian kompetensi pembelajaran. Saat merancang kegiatan kurikulum, guru perlu memahami dimensi pengetahuan itu sendiri, yang dapat membantu guru menentukan bahan ajar yang akan diajarkan kepada siswa dan membimbing guru dalam menentukan apa yang perlu dipelajari siswa (Scristia, 2019).

Dari hasil wawancara dan observasi, bapak ibu guru masih kesulitan dalam menentukan indikator pencapaian hasil belajar. Keputusan Menteri Pendidikan Negara Tahun 2007 (Permendiknas) No. 41 Menurut standar proses, Indikator kompetensi adalah pola perilaku yang dapat diukur dan/atau diamati untuk menunjukkan penguasaan keterampilan dasar tertentu. Poin referensi untuk evaluasi adalah mata pelajaran. Indikator pencapaian kemampuan dirumuskan dengan menggunakan kata kerja fungsional yang terukur, meliputi pengetahuan, sikap, dan keterampilan. Dengan kata lain, Skor Pencapaian Kompetensi adalah pernyataan tentang kemampuan yang harus dimiliki atau ditunjukkan siswa untuk menunjukkan pencapaian suatu kompetensi dasar (KD). Oleh karena itu, indeks pencapaian kompetensi menjadi standar pencapaian KD. Hal ini sejalan dengan tujuan indeks pencapaian kompetensi sebagai kriteria penilaian mata pelajaran.

Demikian juga dengan bapak ibu guru yang memiliki keterbatasan dalam menentukan metode pembelajaran. Dengan adanya kegiatan $\mathrm{KKG} /$ tutor sebaya dapat menambah wawasan atau variasi metode pembelajaran yang bisa dilakukan saat proses pembelajaran secara daring. Apabila kegiatan KKG/tutor sebaya tidak dapat menyelesaikan permasalahan maka perlu dilakukan kegiatan workshop. Kegiatan workshop dengan mengundang narasumber sehingga bapak ibu guru mampu menentukan metode yang sesuai untuk menyampaikan kompetensi dasar yang sudah ditentukan.

Permasalahan tentang etika pembelajaran anak masih ada beberapa anak yang kurang baik etikanya saat mengikuti pembelajaran daring. Beberapa anak masih belum bisa disiplin dalam mengikuti pembelajaran yaitu beberapa anak masih terlambat mengikuti pembelajaran/ join saat google meet, pengumpulan tugas-tugas ke google classroom masih harus ditagih/diminta, harus diingatkan berulang-ulang, ada beberapa anak tidak mau membuka kamera saat meet dikarenakan mengikuti kegiatan pembelajaran sambil tiduran, bermain game, makan snack, atau karena belum mandi. Hal tersebut perlu adanya peran dari orangtua untuk mengingatkan anak-anaknya. Di sisi lain orang tua sibuk bekerja sehingga tidak cukup waktu untuk mengurus atau mendisiplinkan anak-anak. Bisa dikatakan bahwa bapak ibu guru tidak bisa memantau keseriusan anak saat mengikuti kegiatan pembelajaran.

\section{Solusi Permasalahan Implementasi Kurikulum Darurat Pelajaran Pendidikan Pancasila Dan Kewarganegaraan Jenjang Sekolah Dasar}

Etika yang baik dalam mengikuti proses pembelajaran daring bisa terbentuk bila ada kerja sama antara sekolah dengan orangtua. Orang tua dan guru perlu bekerja sama untuk mengajarkan pendidikan karakter dan moral untuk anak-anak (Birhan et al., 2021). Bentuk kerja sama dengan orangtua melalui komunikasi antara guru dengan orangtua, adanya buku penghubung/WA grup orangtua, laporan kegiatan anak kepada orangtua 
792 Analisis Pembaharuan Kurikulum Darurat pada Mata Pelajaran Pendidikan Pancasila dan Kewarganegaraan - Abd. Rohim Asnawi, Kusrini Setyowati, A. Aulia Reski Novianti Alnisyar, Muhammad Holqi Rizki Azhari, Mustiningsih, Agus Timan

DOI: https://doi.org/10.31004/edukatif.v4i1.1824

selama mengikuti kegiatan belajar secara daring (ada buku panduan), menuliskan refleksi harian yang yang dikirim melalui google classroom. Jam perwalian bisa diefektifkan dengan mengadakan video call atau google meet kelompok kecil dengan permasalahan yang sama misalnya kelompok anak yang sering terlambat mengirimkan tugas, kelompok anak yang jarang mengikuti google meet, kelompok anak yang nilainya selalu di bawah KBM dan lain-lain. Tujuan mengadakan google meet kelompok kecil untuk mempersingkat waktu dan memotivasi anak-anak serta bersaing yang sehat antar anak-anak yang memiliki permasalahan sama. ada tantangan dalam memberikan pendidikan karakter dan moral sebagai mata pelajaran tersendiri di sekolah dan kegagalan orang tua dan guru untuk menjadi panutan yang baik bagi anak (Birhan et al., 2021). Disisi lain dengan pendidikan karakter yang berjalan dengan baik dapat memperkuat ikatan orang tua dengan anak (MeiJu et al., 2014).

Masalah sumber daya manusia yang masih terbatas dalam penggunaan IT bisa diselesaikan dengan adanya pelatihan IT atau tutor sebaya. Bisa juga saat pelatihan, bapak ibu guru yang sudah mahir membantu yang masih kesulitan dalam IT. Dengan demikian semua bapak ibu guru dapat memanfaatkan IT dengan baik dan lancar, proses pembelajaran pun dapat berjalan sesuai dengan tujuan yang sudah dibuat. Sejalan juga yang diterngkan oleh Sulstri dkk dalam peneitiannya "Pelatihan Pembuatan Bahan Ajar Dan Media Pembelajaran" Selain mampu menggunakan teknologi untuk mengembangkan alat peraga, ia menjelaskan bahwa tantangan besar lain yang dihadapi guru adalah mereka harus mampu membuat bahan ajar untuk melaksanakan pembelajaran jarak jauh. Masih banyak guru yang belum membuat buku ajar untuk digunakan dalam pembelajaran jarak jauh. Seperti yang terjadi pada guru SD di Pamoulin Timur 02. Banyak guru yang berjuang untuk menggunakan teknologi dan membuat buku teks yang menggunakannya karena mereka tidak muda lagi dan masih sangat melek teknologi (Sulastri et al., 2021).

Dengan demikian solusi yang dapat diberikan yaitu: (1) Kepala sekolah SD katolik Cor Jesu Malang diharapkan agar lebih meningkatkan lagi pendampingan serta mengupayakan peningkatan kualitas para guru baik dari segi perencanaan, pelaksanaan, hingga sampai pengevaluasian pembelajaran pada pembaharuan kurikulum darurat. (2) Guru/ Wali kelas, lebih meningkatkan lagi inovasi dan kreatifitas dalam melaksanakan pembelajaran yang menyenangkan serta memotivasi siswa, guru diharapkan pula untuk mendukung setiap pembaharuan-pembaharuan kurikulum dan meningkatkan kompetensi dan keahlian diri sendiri melalui mengikuti kegiatan workshop atau pelatihan. (3) Penelitian lebih lanjut, penelitian ini berupa pembaruan yang mendesak terhadap kurikulum pada mata pelajaran Pancasila dan mata pelajaran PKn yang relatif baru. pendidikan yang berkualitas di masa depan.

\section{KESIMPULAN}

Hasil penelitian dapat disimpulkan beberapa hal dari permasalahan-permasalahan yang timbul di SD Katolik Cor Jesu Malang tentang pembaharuan kurikulum darurat, seperti guru yang kesulitan dalam menentukan indikator pencapaian hasil belajar, menentukan metode pembelajaran saat online, etika peserta didik dalam proses pembelajaran, kurangnya jam perwalian dalam penyelesaikan permasalahan peserta didik secara individu dan para guru masih terbatas dalam hal Informasi dan Teknologi. Dari adanya permasalah pasti ada solusi, solusi untuk guru yang kesulitan dalam menentukan indikator pencapaian hasil belajar dapat diadakan dengan kegiatan KKG/Kelompok Kerja guru / tutor sebaya atau kegiatan workshop dengan mengundang narasumber. Permasalahan etika peserta didik dalam proses pembelajaran melalui kerja sama antara sekolah dengan orangtua. Jam perwalian bisa diefektifkan dengan mengadakan video call atau google meet kelompok kecil Guru yang masih terbatas dalam hal Informasi dan Teknologi dapat mempercepat pelatihan dan mungkin memerlukan guru lain untuk memiliki lebih banyak keterampilan di bidang informasi dan teknologi. 
793 Analisis Pembaharuan Kurikulum Darurat pada Mata Pelajaran Pendidikan Pancasila dan Kewarganegaraan - Abd. Rohim Asnawi, Kusrini Setyowati, A. Aulia Reski Novianti Alnisyar, Muhammad Holqi Rizki Azhari, Mustiningsih, Agus Timan

DOI: https://doi.org/10.31004/edukatif.v4i1.1824

\section{DAFTAR PUSTAKA}

Akhwani, A., \& Afwan Romdloni, M. (2021). Indonesian Journal Of Primary Education. (C) 2021-Indonesian Journal Of Primary Education, 5(1), 1-12. Https://Doi.Org/Https://Doi.Org/10.17509/Ijpe.V5i1.31381

Birhan, W., Shiferaw, G., Amsalu, A., Tamiru, M., \& Tiruye, H. (2021). Exploring The Context Of Teaching Character Education To Children In Preprimary And Primary Schools. Social Sciences \& Humanities Open, 4(1), 100171. Https://Doi.Org/10.1016/J.Ssaho.2021.100171

Fahmy, R., Bachtiar, N., Rahim, R., \& Malik, M. (2015). Measuring Student Perceptions To Personal Characters Building In Education: An Indonesian Case In Implementing New Curriculum In High School. Procedia - Social And Behavioral Sciences, 211, 851-858. Https://Doi.Org/10.1016/J.Sbspro.2015.11.112

Julaeha, S. (2019). Problematika Kurikulum Dan Pembelajaran Pendidikan Karakter. Jurnal Penelitian Pendidikan Islam, 7(2), 157-182. Https://Doi.Org/Https://Doi.Org/10.36667/Jppi.V7i2.367

Kepmendikbud Nomor 719/P/2020 Tentang Pedoman Pelaksanaan Kurikulum Pada Satuan Pendidikan Dalam Kondisi $\quad$ Khusus, $\quad$ Www.Kemdikbud.Go.Id $\quad 9 \quad$ (2020). Https://Www.Kemdikbud.Go.Id/Main/Blog/2020/08/Kemendikbud-Terbitkan-Kurikulum-Darurat-PadaSatuan-Pendidikan-Dalam-Kondisi-Khusus

Kidd, D., Miner, J., Schein, M., Blauw, M., \& Allen, D. (2020). Ethics Across The Curriculum: Detecting And Describing Emergent Trends In Ethics Education. Studies In Educational Evaluation, 67(October 2019), 100914. Https://Doi.Org/10.1016/J.Stueduc.2020.100914

Kurniawan, A. (2011). Masalah Pendidikan Di Indonesia: Dampak Perubahan Kurikulum. Diperoleh Dari Academia.Edu

Laela, Un, Qomariyah, Snl, \& Abi Aufa, A. (2021). Konsep, Strategi Dan Metode Pendidikan Karakter Di Masa Pandemi Covid 19. Al-Aufa: Jurnal Pendidikan Dan Kajian Keislaman, 3(01), 80-94. Https://Doi.Org/Https://Doi.Org/10.36840/Alaufa.V3i01.441

Maria, R., Rifma, R., \& Syahril, S. (2021). Efektivitas Pembelajaran Dan Pembinaan Karakter Di Masa Pandemi Covid-19. Edukatif: Jurnal Ilmu Pendidikan, 3(4), 1503-1512. Https://Doi.Org/Https://Doi.Org/10.31004/Edukatif.V3i4.566.

Masykur. (2019). Teori Dan Telaah Pengembangan Kurikulum. Cv. Anugrah Utama Raharja.

Mei-Ju, C., Chen-Hsin, Y., \& Pin-Chen, H. (2014). The Beauty Of Character Education On Preschool Children's Parent-Child Relationship. Procedia - Social And Behavioral Sciences, 143, 527-533. Https://Doi.Org/10.1016/J.Sbspro.2014.07.431

Perdana, D. R., \& Adha, M. M. (2020). Implementasi Blended Learning Untuk Penguatan Pendidikan Karakter Pada Pembelajaran Pendidikan Kewarganegaraan. Citizenship Jurnal Pancasila Dan Kewarganegaraan, 8(2), 90-101. Https://Doi.Org/Http://Doi.Org/10.25273/Citizenship.V8i2.6168

Rachman, F., Nurgiansyah, T. H., \& Kabatiah, M. (2021). Profilisasi Pendidikan Kewarganegaraan Dalam Kurikulum Pendidikan Indonesia. Edukatif: Jurnal Ilmu Pendidikan, 3(5), 2970-2984. Https://Doi.Org/Https://Doi.Org/10.31004/Edukatif.V3i5.1052

Scristia, S. (2019). Analisis Kesesuaian Indikator Terhadap Kompetensi Dasar Pada Pelajaran Matematika Oleh Guru Sekolah Menengah Palembang. Jurnal Gantang, 4(2), 103-109. Https://Doi.Org/Https://Doi.Org/10.31629/Jg.V4i2.1429

Sudarman. (2019). Pengembangan Kurikulum : Kajian Teori Dan Praktik. Mulawarman University Press.

Sulastri, Nurdiyana, Setiawati, Suanto, \& Rustandi, R. (2021). Pelatihan Pembuatan Bahan Ajar Dan Media 
794 Analisis Pembaharuan Kurikulum Darurat pada Mata Pelajaran Pendidikan Pancasila dan Kewarganegaraan - Abd. Rohim Asnawi, Kusrini Setyowati, A. Aulia Reski Novianti Alnisyar, Muhammad Holqi Rizki Azhari, Mustiningsih, Agus Timan DOI: https://doi.org/10.31004/edukatif.v4i1.1824

Pembelajaran. Pro Bono Jurnal Pengabdian Kepada Masyarakat, 1(2), 1-7.

Suriadi, H. J., Firman, F., \& Ahmad, R. (2021). Analisis Problema Pembelajaran Daring Terhadap Pendidikan Karakter Peserta Didik. Edukatif: Jurnal Ilmu Pendidikan, 3(1), 165-173. Https://Doi.Org/10.31004/Edukatif.V3i1.251 